\title{
Statistical Analysis of Age Reporting Errors by Insured and Uninsured Patients in Cape Coast Teaching Hospital of Ghana
}

\author{
Eyiah-Bediako Francis ${ }^{1}$, Bosson-Amedenu Senyefia ${ }^{2}$, Borbor Bridget Sena ${ }^{3}$ \\ ${ }^{1}$ Department of Statistics, University of Cape Coast, Cape Coast, Ghana \\ ${ }^{2}$ Department of Mathematics and ICT, Holy Child College of Education, Takoradi, Ghana \\ ${ }^{3}$ Department of Mathematical Sciences, University of Mines and Technology, Tarkwa, Ghana
}

Email address:

senyefia@yahoo.com (Bosson-Amedenu S.)

\section{To cite this article:}

Eyiah-Bediako Francis, Bosson-Amedenu Senyefia, Borbor Bridget Sena. Statistical Analysis of Age Reporting Errors by Insured and Uninsured Patients in Cape Coast Teaching Hospital of Ghana. Biomedical Statistics and Informatics. Vol. 4, No. 2, 2019 , pp. 15-21. doi: $10.11648 /$ j.bsi.20190402.11

Received: July 12, 2019; Accepted: August 4, 2019; Published: August 15, 2019

\begin{abstract}
Age is a very important variable that guides clinicians to carryout diagnosis, treatment, as well as administering medical procedures to patients. Misreporting of age by patients to clinicians can have dire consequences on the patients' health. This retrospective study used a 10 year demographic data involving the ages reported by 906,383 patients. Demographic indexes such as Whipples, Myers Blended and Joint Score were employed to analyse reported ages among insured and uninsured patients at the Cape Coast Teaching Hospital. The computed joint score values of 76.88 and 85.60 respectively for uninsured and insured patients qualified the data as highly inaccurate by the standards of interpretation of UN index. The summary of the digit preference of the uninsured and insured patients by Myers blended index approach were 29.34 and 29.87 respectively. The blended sum at the digits $0,1,2$ and 5 exceeded $10 \%$ of the total blended population, an indication of over selection of ages ending in those digits by the insured and uninsured patients. Whipple's index for uninsured and insured patients was 149.3 and 287.1 respectively. These values respectively show that the reliability of the ages reported were rough and very rough, by the Whipple's index interpretation standards. The insured were found to have higher tendency of concentrating on ages ending in 0 and 5 than the uninsured. The study concluded that age data in Cape Coast Teaching Hospital is misreported and inaccurate and if not adjusted may result in wrong agedependent medical procedures undertaken by clinicians. It was recommended among others for hospitals to institute innovative ways of recording ages such as using calendar of historical events technique where the patients could not recall their correct age.
\end{abstract}

Keywords: Myers Index, Whipples Index, UN Index, Hospital, Insured, Uninsured, Demographic Indexes

\section{Introduction}

Demographic indexes such as Whipples index, Myers Blended index and UN index have been widely used in measuring the quality of age data in diverse disciplines. Many reasons account for misreporting of age, these include: (a) Ignorance of correct Age-most especially illiterate population (b) Carelessness in reporting and in recording age (c) There is tendency to record or state age ending in certain figures known as preferred digits e.g age ending in 0 or 5 (d) There is a possible sub-conscious aversion to certain numbers (e) Exaggeration of length of life at advance ages (f) Misplacement of age, from some motive such as economic, social, political or purely personal [1-6].

Bwalya et al. (2015), [7] applied demographic indexes to assess if there had been improvement in the quality of age data with respect to three consecutive population censuses (1969, 1990 and 2010) in Zambia. Data was collected in single years and the Whipples, Myers Blended and UN joint score indexes were applied to the data. The study found improvement in the quality of data collected in successive censuses. That notwithstanding, digit preference of 0 and 5 
were still found to be persisting in Zambia.

Bekele (2006), [8] used demographic indexes to measure the quality of data in two consecutive censuses in Ethiopia. The results showed that the quality of the data was reduced in the in the second census which was contrary to expectation. Bosson-Amedenu et.al (2019), [9] in their study analysed the quality of age data reported by Health Insurance Scheme registrants for the month of June, 2018 in the SekondiTakoradi District of Ghana. The results showed among others that the quality of data reported was highly inaccurate with a UN index value of 138.14 .

Pardeshi (2010), [10] applied demographic indexes in a cross-sectional study at Yavatmal district of India. The results showed among others that the Whipples index for terminal digits of " 0 " and "5" were determined to be 386.71 and 382.74 respectively. It was concluded that the ages reported were of poor quality. Bello (2012), [11] studied the ages of patients collected at the outpatients department of Dutsin-ma General Hospital, Katsina State of Nigeria, in January 2012 using demographic techniques. From the results, the accuracy of the ages reported was very rough in quality for both male and female ages reported. For the Myer's index, about 86 percent of male outpatients and 88 percent of female outpatients reported their ages with incorrect final digits.

Although a lot of studies have applied the concept of demographic indexes in other disciplines, not enough work has been done in the Health sector to find out the quality of age data reported to clinicians by their patients. Misreporting of ages by patients can have a great influence on the prescriptions by clinicians which inadvertently will have negative effect on the patients.

\section{Method}

A retrospective demographic data of 906,383 patients who visited the Cape Coast Teaching Hospital from the years January 2008 through to December 2017 were analysed for age reporting errors using demographic indexes. The data was in the form of single years of age and was also put in the form of five year age intervals. The research sought to determine the error of age reporting by the method of demographic indexes. The Whipples, Myers and Joint score indexes were used to determine the age heaping among patients. Microsoft Excel was employed in the analysis of the data.

\subsection{Whipples Index}

The Whipples index was used to measure the preference for or avoidance of a particular digit. This index operates on the assumption of rectangularity or of linearity of five year age range. Age heaping on terminal digits of 0 and 5 put together in the age range 23-62 may be measured by comparing the sum of the population at ages in this range ending in zero and five with one fifth of the total population in the age range.

$$
\text { Whipples Index }=\frac{P_{25}+P_{30}+P_{35}+P_{40}+\cdots+P_{55}+P_{60}}{\frac{1}{5}\left(P_{23}+P_{24}+P_{25}+\cdots+P_{61}+P_{62}\right.} \times 100
$$

or

$$
\text { Whipples Index }=\frac{\sum_{23}^{62} P_{a} \text { ending } \text { in }^{\prime} 0^{\prime} \text { or }^{\prime} 5^{\prime}}{\frac{1}{5} \sum_{23}^{62} P_{a}} \times 100
$$

\subsection{Myers Index}

Myers index is one of the widely used methods of measuring age preference at each digit. It is useful in measuring the accuracy of age data. This index is used to measure the preference or dislike for each of the ten digits in age reporting. It is applicable when age data is in single years. It is referred to as blended index since it was developed to avoid the bias in the computed index. This bias is attributed to the Whipples index since for example, the terminal digit of numbers are more likely to be 0 than 1 and 9. The overall Myers summary index for all terminal digits is computed as one-half of the sums of absolute deviations from $10 \%$. The range of the index are between 0 and 90 .

The Myers blended index is given by:

$$
\text { Myers Blended Index }=\left[\sum_{i=0}^{9} \frac{B_{i}}{\sum_{i=0}^{9} B_{i}} \times 100\right]-10 \%
$$

$B_{i}$ is the Blended population $i$ ranging from $0-9$

$$
\begin{gathered}
\text { Grand Blended population }=\sum_{i=0}^{9} B_{i} \\
\text { Magnitude of preference }=\left[\sum_{i=0}^{9} \frac{B_{i}}{\sum_{i=0}^{9} B_{i}} \times 100\right]_{-10}
\end{gathered}
$$

\subsection{United Nations Index (Joint Score or Age Accuracy Index)}

This index simultaneously uses age-sex ratios in its computation. Age and sex ratios are computed for five-year age groups up to about 70 . With respect to the sex ratios; successive differences between consecutive age groups are found and the average taken after finding the absolute sum. With respect to the age ratios of either sex, deviations from 100 are computed; disregarding the sign, the sum is computed [12-15]. The mean of the deviations of the two age ratios ARS (M) and ARS (F) are then summed to 3 times of the mean of the sex ratio differences (SRS). Hence, the UN Joint score is computed as:

$$
\text { Joint Score }=A R S(M)+A R S(F)+3(S R S)
$$


Table 1. United Nations Index (Joint Score) Computation of Reporting errors by noninsured Patients.

\begin{tabular}{|c|c|c|c|c|c|c|c|c|}
\hline $\begin{array}{l}\text { Terminal } \\
\text { Digits }\end{array}$ & $\begin{array}{l}\text { Male } \\
\text { Population }\end{array}$ & Age Ratio & $\begin{array}{l}\text { Deviation } \\
\text { from } 100\end{array}$ & $\begin{array}{l}\text { Female } \\
\text { Population } \\
\end{array}$ & Age Ratio & $\begin{array}{l}\text { Deviation } \\
\text { from } 100\end{array}$ & Sex Ratio & $\begin{array}{l}\text { Successive } \\
\text { Difference }\end{array}$ \\
\hline $0-4$ & 10351 & & & 11462 & & & 90.30710173 & \\
\hline $5-9$ & 5544 & 72.4990 & -27.5010 & 5668 & 66.6314 & -33.3686 & 97.81227946 & -7.50518 \\
\hline $10-14$ & 4943 & 69.9597 & -30.0403 & 5551 & 71.1302 & -28.8698 & 89.04701856 & 8.765261 \\
\hline $15-19$ & 8587 & 189.7470 & 89.7470 & 9940 & 179.0830 & 79.0830 & 86.38832998 & 2.658689 \\
\hline $20-24$ & 4108 & 67.2671 & -32.7329 & 5550 & 74.7978 & -25.2022 & 74.01801802 & 12.37031 \\
\hline $25-29$ & 3627 & 102.4721 & 2.4721 & 4900 & 102.4569 & 2.4569 & 74.02040816 & -0.00239 \\
\hline $30-34$ & 2971 & 84.0096 & -15.9904 & 4015 & 89.0540 & -10.9460 & 73.99750934 & 0.022899 \\
\hline $35-39$ & 3446 & 118.3582 & 18.3582 & 4117 & 110.9404 & 10.9404 & 83.70172456 & -9.70422 \\
\hline $40-44$ & 2852 & 100.0000 & 0.0000 & 3407 & 99.9853 & -0.0147 & 83.71000881 & -0.00828 \\
\hline $45-49$ & 2258 & 70.6729 & -29.3271 & 2698 & 67.3995 & -32.6005 & 83.69162342 & 0.018385 \\
\hline $50-54$ & 3538 & 159.2618 & 59.2618 & 4599 & 166.0589 & 66.0589 & 76.92976734 & 6.761856 \\
\hline $55-59$ & 2185 & 67.9627 & -32.0373 & 2841 & 71.5978 & -28.4022 & 76.90953889 & 0.020228 \\
\hline $60-64$ & 2892 & 144.1316 & 44.1316 & 3337 & 134.8828 & 34.8828 & 86.66466886 & -9.75513 \\
\hline $70+$ & 4530 & & & 5688 & & & & \\
\hline Absolute Total & & & 432.3407 & & & 406.1335 & & 57.68659 \\
\hline AVERAGE & & & 33.25698 & & & 31.24104 & & 4.43743 \\
\hline JOINT SCORE & 77.81 & & & & & & & \\
\hline
\end{tabular}

The joint score value of 76.88 qualifies the data as highly inaccurate by the standards of interpretation of UN index. The female noninsured patients reported more inaccurate ages than their male counterparts; evidenced from the magnitude of their absolute deviations (424.13 > 402.11). Male and female patients within the age group of 15-19 and 50-54 reported the most inaccurate ages.

Table 2. United Nations Index (Joint Score) Computation of Reporting errors by Insured Patients.

\begin{tabular}{|c|c|c|c|c|c|c|c|c|}
\hline $\begin{array}{l}\text { Terminal } \\
\text { Digits }\end{array}$ & $\begin{array}{l}\text { Male } \\
\text { Population }\end{array}$ & Age Ratio & $\begin{array}{l}\text { Deviation } \\
\text { from } 100\end{array}$ & $\begin{array}{l}\text { Female } \\
\text { Population }\end{array}$ & Age Ratio & $\begin{array}{l}\text { Deviation } \\
\text { from } 100\end{array}$ & Sex Ratio & $\begin{array}{l}\text { Successive } \\
\text { Difference }\end{array}$ \\
\hline $0-4$ & 44221 & & & 11462 & & & -37.1355 & \\
\hline $5-9$ & 19185 & 62.7125 & -37.2875 & 5668 & 62.8645 & -37.1355 & -36.8878 & 6.5977 \\
\hline $10-14$ & 16963 & 66.8796 & -33.1204 & 5551 & 63.1122 & -36.8878 & 18.8553 & 13.2674 \\
\hline $15-19$ & 31542 & 164.2086 & 64.2086 & 9940 & 118.8553 & 18.8553 & 17.7075 & 13.1635 \\
\hline $20-24$ & 21454 & 84.9899 & -15.0101 & 5550 & 117.7075 & 17.7075 & 2.4685 & 33.3518 \\
\hline $25-29$ & 18944 & 102.4720 & 2.4720 & 4900 & 102.4685 & 2.4685 & -8.6565 & -0.0018 \\
\hline $30-34$ & 15520 & 82.5400 & -17.4600 & 4015 & 91.3435 & -8.6565 & 7.5483 & 0.0010 \\
\hline $35-39$ & 18662 & 120.5400 & 20.5400 & 4117 & 107.5483 & 7.5483 & 0.0000 & -10.0295 \\
\hline $40-44$ & 15444 & 100.0000 & 0.0000 & 3407 & 100.0000 & 0.0000 & -34.9545 & 0.0011 \\
\hline $45-49$ & 12226 & 59.1113 & -40.8887 & 2698 & 65.0455 & -34.9545 & 70.9934 & 0.0017 \\
\hline $50-54$ & 25922 & 183.6031 & 83.6031 & 4599 & 170.9934 & 70.9934 & -27.6096 & -8.7986 \\
\hline $55-59$ & 16011 & 64.3736 & -35.6264 & 2841 & 72.3904 & -27.6096 & 32.8087 & -0.0023 \\
\hline $60-64$ & 23822 & 153.4132 & 53.4132 & 3337 & 132.8087 & 32.8087 & -48.9311 & -18.1872 \\
\hline $65-69$ & 15045 & 45.6020 & -54.3980 & 2107 & 51.0689 & -48.9311 & -37.1355 & 0.0038 \\
\hline $70+$ & 42162 & & & 5688 & & & & \\
\hline Absolute Total & & & 458.0279 & & & 344.5567 & & 103.4074 \\
\hline AVERAGE & & & 35.23292 & & & 26.50436 & & 7.954415 \\
\hline JOINT SCORE & 85.60 & & & & & & & \\
\hline
\end{tabular}

Again joint score value of 85.60 qualifies the data as highly inaccurate by the standards of interpretation of UN index. The male insured patients reported more inaccurate ages than their female counterparts; evidenced from the magnitude of their absolute deviations $(458.0279>344.5567)$. Male patients within the age group of 50-54 and 15-19 reported the most inaccurate ages. Also female patients within the age group of 5054 and 65-69 reported the most inaccurate ages.

Discussions on Tables 1 and 2.

It has been established from the analysis by Joint Score approach of detection of age reporting error that the insured patients wrongly reported their ages more than the insured patients; evidenced by the comparing the sum of absolute deviations. Whereas the male and female patients within the age groups of 15-19 and 50-54 reported the most inaccurate ages in the case of the noninsured patients, male patients within the age group of 50-54 and 15-19 reported the most inaccurate ages among the insured. Again, female patients within the age group of 50-54 and 65-69 reported the most inaccurate ages among the insured. 
Cape Coast Teaching Hospital of Ghana

Table 3. Computation of reporting errors by Uninsured Patients by Myers Blended Index.

\begin{tabular}{|c|c|c|c|c|c|c|c|c|c|}
\hline $\begin{array}{l}\text { Terminal } \\
\text { Digit }\end{array}$ & $\begin{array}{l}\text { Sum of } \\
\text { ages 10-89 }\end{array}$ & Coefficient & $\begin{array}{l}\text { Ages 10-89 } \\
\text { Coefficient } \\
\text { Product }\end{array}$ & $\begin{array}{l}\text { Sum of } \\
\text { ages 20-89 }\end{array}$ & Coefficient & $\begin{array}{l}\text { Ages 20-89 } \\
\text { Coefficient } \\
\text { Product }\end{array}$ & $\begin{array}{l}\text { Blended } \\
\text { Sum }\end{array}$ & $\begin{array}{l}\% \\
\text { Distribution }\end{array}$ & $\begin{array}{l}\text { Deviation } \\
\text { from } 10\end{array}$ \\
\hline 0 & 7147 & 1 & 7147 & 5209 & 9 & 46877 & 52086 & 32.23 & 22.23 \\
\hline 1 & 3452 & 2 & 6904 & 2180 & 8 & 17443 & 19623 & 12.14 & 2.14 \\
\hline 2 & 4603 & 3 & 13809 & 2847 & 7 & 19926 & 22772 & 14.09 & 4.09 \\
\hline 3 & 3634 & 4 & 14536 & 2301 & 6 & 13809 & 16110 & 9.97 & -0.03 \\
\hline 4 & 3452 & 5 & 17261 & 2120 & 5 & 10599 & 12719 & 7.87 & -2.13 \\
\hline 5 & 4785 & 6 & 28708 & 3513 & 4 & 14051 & 17564 & 10.87 & 0.87 \\
\hline 6 & 3271 & 7 & 22894 & 1999 & 3 & 5996 & 7995 & 4.95 & -5.05 \\
\hline 7 & 3210 & 8 & 25680 & 1999 & 2 & 3997 & 5996 & 3.71 & -6.29 \\
\hline 8 & 3937 & 9 & 35431 & 2483 & 1 & 2483 & 4966 & 3.07 & -6.93 \\
\hline \multirow[t]{3}{*}{9} & 2847 & 10 & 28466 & 1756 & 0 & 0 & 1756 & 1.09 & -8.91 \\
\hline & & & & & & & 161587 & 100 & 58.68 \\
\hline & & & \multicolumn{5}{|c|}{ Summary Index of Age preference } & Total Index & 29.34 \\
\hline
\end{tabular}

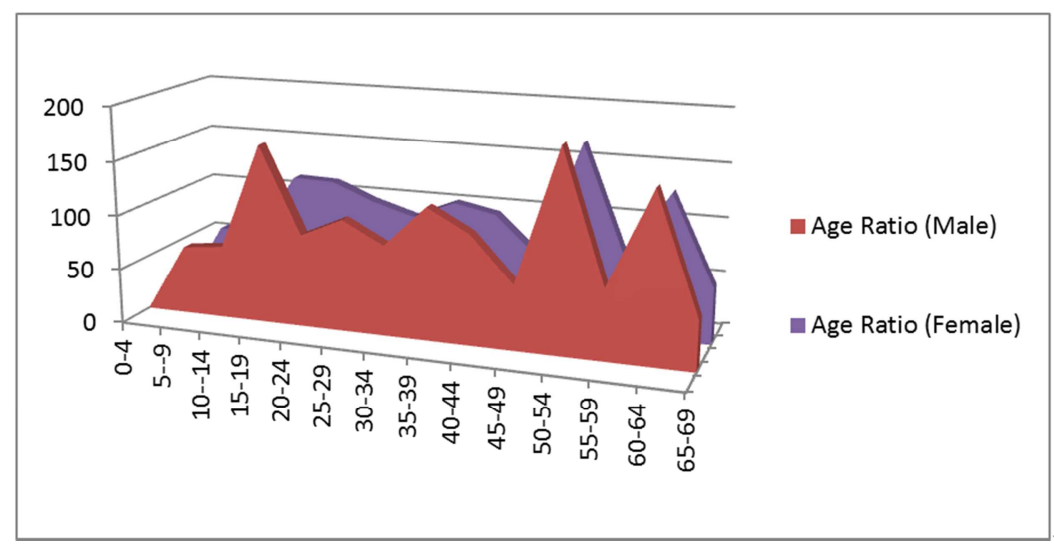

Figure 1. Age Ratio Distribution of Insured Male and Female.

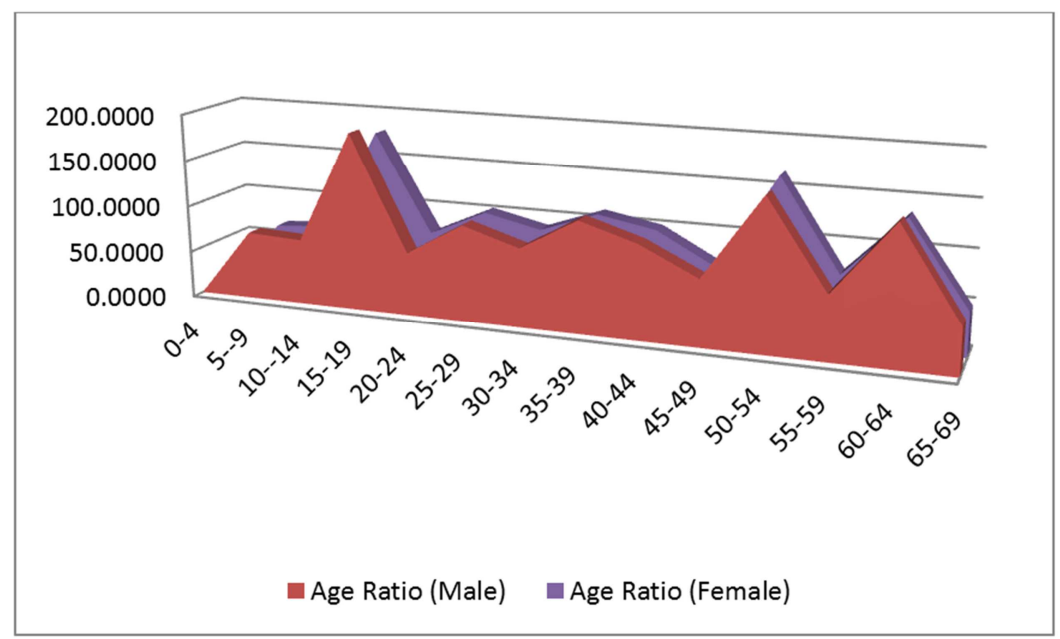

Figure 2. Age Ratio Distribution of uninsured Male and Female.

The use of the Myer's index was to facilitate in measuring the preference of the dislikes for each of the ten digits by the uninsured patients. The overall Myers summary index for all terminal digits is computed as one-half of the sum of absolute deviations from $10 \%$. The results of the computation found the summary of the preference of the uninsured patients to be 29.34. About $59 \%$ of uninsured patients reported their ages with incorrect terminal digits. This is an indication that of a serious prevalence of age heaping among uninsured patients.
The results further showed that there was more preference for the terminal digit of $0(32 \%)$. The digit of 9 was the least preferred terminal digit. The blended sum at the digits $0,1,2$ and 5 exceeded $10 \%$ (representing 16,159) of the total blended population, an indication of over selection of ages ending in those digits by both the uninsured patients. On the other hand there was under-selection of the remaining digits as their respective blended sums were less than $10 \%$ of the total blended population. The index was not approximately 
zero, an indication of presence of age heaping.

Table 4. Computation of reporting errors by insured Patients by Myers Blended Index.

\begin{tabular}{|c|c|c|c|c|c|c|c|c|c|}
\hline $\begin{array}{l}\text { Terminal } \\
\text { Digit }\end{array}$ & $\begin{array}{l}\text { Sum of ages } \\
10-89\end{array}$ & Coefficient & $\begin{array}{l}\text { Ages 10-89 } \\
\text { Coefficient } \\
\text { Product }\end{array}$ & $\begin{array}{l}\text { Sum of ages } \\
20-89\end{array}$ & Coefficient & $\begin{array}{l}\text { Ages 20-89 } \\
\text { Coefficient } \\
\text { Product }\end{array}$ & $\begin{array}{l}\text { Blended } \\
\text { Sum }\end{array}$ & $\begin{array}{l}\% \\
\text { Distribution }\end{array}$ & $\begin{array}{l}\text { Deviation } \\
\text { from } 10\end{array}$ \\
\hline 0 & 99807 & 1 & 99807 & 59207 & 9 & 532865 & 592073 & 26.24 & 16.24 \\
\hline 1 & 48212 & 2 & 96423 & 33833 & 8 & 270662 & 304494 & 13.49 & 3.49 \\
\hline 2 & 64282 & 3 & 192847 & 49057 & 7 & 343402 & 392460 & 17.39 & 7.39 \\
\hline 3 & 50749 & 4 & 202996 & 30449 & 6 & 182697 & 213146 & 9.45 & -0.55 \\
\hline 4 & 48212 & 5 & 241058 & 33833 & 5 & 169164 & 202996 & 9.00 & -1.00 \\
\hline 5 & 66820 & 6 & 400918 & 57516 & 4 & 230062 & 287578 & 12.74 & 2.74 \\
\hline 6 & 45674 & 7 & 319719 & 25375 & 3 & 76124 & 101498 & 4.50 & -5.50 \\
\hline 7 & 44828 & 8 & 358627 & 22245 & 2 & 44490 & 66735 & 2.96 & -7.04 \\
\hline 8 & 54978 & 9 & 494804 & 35524 & 1 & 35524 & 71049 & 3.15 & -6.85 \\
\hline \multirow[t]{3}{*}{9} & 39753 & 10 & 397534 & 24529 & 0 & 0 & 24529 & 1.09 & -8.91 \\
\hline & & & 58.92 & & & & 2256558 & 100 & 59.73 \\
\hline & & & \multicolumn{4}{|c|}{ Summary Index of Age preference } & & Total Index & 29.87 \\
\hline
\end{tabular}

Again, the findings show that the summary of the preference of the insured patients to be 29.87 . About $60 \%$ of insured patients reported their ages with incorrect terminal digits. This is further an indication of a serious prevalence of age heaping among insured patients. It could be inferred from the results that there was more preference for the terminal digit of $0(26 \%)$. The digit of 9 was again the least preferred terminal digit. The blended sum at the digits $0,1,2$ and 5 exceeded $10 \%$ (representing 225,656 ) of the total blended population, an indication of over selection of ages ending in those digits by the insured patients. On the other hand there was under-selection of the remaining digits as their respective blended sums were less than $10 \%$ of the total blended population. The index was not approximately zero, an indication of presence of age heaping.

Table 5. Computation of reporting errors by uninsured Patients by Whipple's Index.

\begin{tabular}{|c|c|c|c|}
\hline Age & Number of Uninsured Patients & Age & Number of Uninsured Patients \\
\hline 23 & 1017 & 25 & 1163 \\
\hline 24 & 945 & 30 & 1199 \\
\hline $25-29$ & 3627 & 35 & 896 \\
\hline $30-34$ & 2971 & 40 & 969 \\
\hline $35-39$ & 3446 & 45 & 715 \\
\hline $40-44$ & 2852 & 50 & 703 \\
\hline $45-49$ & 2258 & 55 & 369 \\
\hline $50-54$ & 3538 & 60 & 618 \\
\hline $55-59$ & 2185 & TOTAL & 6632 \\
\hline 60 & 618 & \multirow{4}{*}{ Digit Preference for ' 0 ' and ' 5 ' digits $=$} & \multirow{4}{*}{$\frac{6632}{\frac{1}{5}(23639)} \times 100=140.3$} \\
\hline 61 & 73 & & \\
\hline 62 & 109 & & \\
\hline TOTAL & 23639 & & \\
\hline
\end{tabular}

Table 6. Computation of reporting errors by insured Patients by Whipple's Index.

\begin{tabular}{llll}
\hline Age & Number of insured Patients & Age & Number of Uninsured Patients \\
\hline 23 & 14210 & 25 & 16240 \\
24 & 13195 & 30 & 16747 \\
$25-29$ & 18944 & 35 & 12518 \\
$30-34$ & 15520 & 40 & 13533 \\
$35-39$ & 18662 & 45 & 9981 \\
$40-44$ & 15444 & 50 & 9811 \\
$45-49$ & 12226 & 55 & 5159 \\
$50-54$ & 25922 & 60 & 8627 \\
$55-59$ & 16011 & TOTAL & 92617 \\
60 & 8627 & & 92617 \\
61 & 1015 & Digit Preference for ' 0 ' and ' 5 'digits $=\frac{91}{\frac{1}{5}(161298)} \times 100=287.1$ \\
62 & 1522 & & \\
TOTAL & 161298 & & \\
\hline
\end{tabular}


The results from tables 5 and 6 show that the whipple's index for uninsured and insured patients are 149.3 and 287.1 respectively. These values respectively show that the reliability of the ages reported were rough and very rough, by the whipple's index interpretation standards. It can be inferred that the ages reported by the uninsured patients were of better quality compared to that of the insured. The insured have higher tendency of concentrating on ages ending in 0 and 5 than the uninsured. This may be due to high illiteracy rate among the insured.

\section{Conclusion}

Demographic indexes such as Whipples, Myers Blended and Joint Score were employed to analyse reporting errors among insured and uninsured patients at the Cape Coast Teaching Hospital. The computed joint score values of 76.88 and 85.60 respectively for noninsured and insured patients qualified the data as highly inaccurate by the standards of interpretation of UN index. The female noninsured patients reported more inaccurate ages than their male counterparts; evidenced from the magnitude of their absolute deviations $(424.13>402.11)$. Male and female patients within the age group of 15-19 and 50-54 reported the most inaccurate ages. The male insured patients reported more inaccurate ages than their female counterparts; evidenced from the magnitude of their absolute deviations $(458.0279>344.5567)$. Male patients within the age group of 50-54 and 15-19 reported the most inaccurate ages. Also female patients within the age group of 50-54 and 65-69 reported the most inaccurate ages. The summary of the digit preference of the uninsured and insured patients by Myers blended index approach was 29.34 and 29.87 respectively. The blended sum at the digits $0,1,2$ and 5 exceeded $10 \%$ of the total blended population, an indication of over selection of ages ending in those digits by the insured and uninsured patients. Whipple's index for uninsured and insured patients was 149.3 and 287.1 respectively. About $59 \%$ of uninsured patients reported their ages with incorrect terminal digits. This is an indication that of a serious prevalence of age heaping among uninsured patients. The results further showed that there was more preference for the terminal digit of $0(32 \%)$. The digit of 9 was the least preferred terminal digit. The blended sum at the digits $0,1,2$ and 5 exceeded 10\% (representing 16,159) of the total blended population, an indication of over selection of ages ending in those digits by both the uninsured patients. On the other hand there was under-selection of the remaining digits as their respective blended sums were less than $10 \%$ of the total blended population. The index was not approximately zero, an indication of presence of age heaping. About $60 \%$ of insured patients reported their ages with incorrect terminal digits. This is further an indication of a serious prevalence of age heaping among insured patients. It could be inferred from the results that there was more preference for the terminal digit of $0(26 \%)$. The digit of 9 was again the least preferred terminal digit. The blended sum at the digits $0,1,2$ and 5 exceeded 10\% (representing 225, 656) of the total blended population, an indication of over selection of ages ending in those digits by the insured patients. On the other hand there was under-selection of the remaining digits as their respective blended sums were less than $10 \%$ of the total blended population. The index was not approximately zero, an indication of presence of age heaping. These values respectively show that the reliability of the ages reported were rough and very rough, by the Whipple's index interpretation standards. The insured were found to have higher tendency of concentrating on ages ending in 0 and 5 than the uninsured. The study recommended among others for hospitals to institute innovative ways of recording ages such as using calendar of historical events technique where the patients could not recall correct their correct age.

\section{Recommendations}

The study recommended for health practitioners to find innovative ways of crosschecking reported ages before taking records of them.

\section{References}

[1] Pardeshi, G. S. (2010), Age heaping and accuracy of age data collected during a community survey in the Yavatmal district, Maharashtra, Indian J Community Med, 35 (3) 391-395.

[2] Shirley. L., V. Ravi and M. Margaret, (2004). An evaluation of the age and sex data from the census population of Canada, provinces and territories, 1971 to 2001, Canadian Population Society Annual Meeting, Winnipeg, Manitoba, (2004). $\mathrm{http} /$ /web.uvic.ca/ canpop/2004/Loh-Verma-MichalowskiCPS04.ppt.

[3] S. Denic, F. Khatib and H. Saadi, Quality of age data in patients from developing countries, Journal of Public Health, 26 (2) (2003), 168-171.

[4] Bello Y., (2012). Error Detection in Outpatients' Age Data Using Demographic Techniques. International Journal of Pure and Applied Sciences and Technology. Int. J. Pure Appl. Sci. Technol., 10 (1) (2012), 27-36. ISSN 2229-6107. Available online at www.ijopaasat.in.

[5] Barua, R. K (2015). Detection of Digit Preference and Age Misreporting by using Demographic Techniques. A thesis submitted in partial fulfillment of the requirements for the degree of Master of Population, Reproductive Health, Gender and Development (MPRHGD) at East West University, Dhaka, Bangladesh.

[6] Kpedekpo G. M. K. (1982). Essentials of Demographic Analysis for Africa. Hernerman Educational Books Inc., ew Hemisphere.

[7] Bwalya B. B, Phiri M. and Mwansa C. (2015). International Journal of Current Advanced Research vol 4, Issue 5, pp 9297, May 2015.

[8] Bekele S. (2006). Analysis on the quality of age and sex data collected in two population and housing censuses of Ethiopia. EthiopJournal of Science, 29 (2): 123-132, 2006. ISSN: 0379-2897. 
[9] Bosson-Amedenu S., Oduro-Okyireh T., Osei-Asibey E. Detection of errors in age data of National Health Insurance Scheme registrants in Ghana: demographic indexes approach. International Journal of Mathematical Archive-10 (3), 2019, 613 Available online through www.ijma.info ISSN 2229-5046.

[10] Pardeshi G. S (2010). Age Heaping and Accuracy of Age Data Collected During a Community Survey in the Yavatmal District, Maharashtra. Indian Journal of Community Medicine 35 (3): 391-5.

[11] Bello Y. (2012). Error Detection in Outpatients' Age Data Using Demographic Techniques. Int. J. Pure Appl. Sci. Technol., 10 (1) (2012), pp. 27-36.
[12] G. M. K. Kpedekpo, Essentials of Demographic Analysis for Africa, Hernerman Educational Books Inc., New Hemisphere, 1982.

[13] B. Kestenbaum, A description of the extreme age population based on improved Medicare enrollment data, Demography, 29 (1992), 565-580.

[14] H. S. Shryock, J. S. Siegel and Associates. The Methods and Materials of Demography, Condensed edition by Edward G. Stockewell, Academic Press, New York, 1976.

[15] I. Johannes and F. Polly, Bancroft's Introduction to Biostatistics, (2nd Edition), Harper and Row publishers, NewYork, 1970. 